\title{
Characteristics and treatment of patients with G3 gastroenteropancreatic neuroendocrine neoplasms
}

\author{
M Heetfeld, C N Chougnet ${ }^{1}$, I H Olsen ${ }^{2}$, A Rinke ${ }^{3}$, I Borbath ${ }^{4}$, G Crespo ${ }^{5}$, J Barriuso ${ }^{6}$, \\ M Pavel, D O'Toole', T Walter ${ }^{8}$ and other Knowledge Network members* \\ Department of Hepatology and Gastroenterology, Charité University Hospital Berlin, Berlin, Germany \\ ${ }^{1}$ Department of Nuclear Medicine, Hopital Saint Louis, Paris, France \\ ${ }^{2}$ Department of Surgical Gastroenterology, European NET Center of Excellence, Rigshospitalet, Denmark \\ ${ }^{3}$ Department of Internal Medicine, Division of Gastroenterology and Endocrinology, \\ Philipps University, Marburg, Germany \\ ${ }^{4}$ Department of Gastroenterology, Cliniques Universitaires Saint-Luc, Bruxelles, Belgium \\ ${ }^{5}$ Department of Medical Oncology, Hospital Universitario de Burgos, Burgos, Spain \\ ${ }^{6}$ Department of Medical Oncology, Hospital Univeristario La Paz, Madrid, Spain \\ ${ }^{7}$ Department of Clinical Medicine and Gastroenterology, St James's and St Vincent's Hospitals and TCD, \\ Dublin, Ireland \\ ${ }^{8}$ Department of Hepatology and Gastroenterology, Edouard Herriot Hospital, University of Lyon, \\ 69437 Lyon Cedex 03, France \\ *(details of other Knowledge Network members are given in the Acknowledgement section)
}

Correspondence should be addressed to T Walter Email

thomas.walter@chu-lyon.fr

\begin{abstract}
Data on gastroenteropancreatic neuroendocrine neoplasms (NEN) G3 (well-differentiated neuroendocrine tumors (NET G3) and neuroendocrine carcinoma (NEC)) are limited.

We retrospectively study patients with NET G3 and NEC from eight European centers.

Data examined included clinical and pathological characteristics at diagnosis, therapies and outcomes. Two hundred and four patients were analyzed (37 NET G3 and 167 NEC).

Median age was 64 (21-89) years. Tumor origin included pancreas (32\%) and colon-rectum (27\%). The primary tumor was resected in $82(40 \%)$ patients. Metastatic disease was evident at diagnosis in 88\% (liver metastases: 67\%). Median Ki-67 index was 70\% (30\% in NET G3 and $80 \%$ in NEC; $P<0.001)$. Median overall survival (OS) for all patients was 23 (95\% Cl: $18-28)$ months and significantly higher in NET G3 (99 vs 17 months in NEC; HR=8.3; $P<0.001$ ). Platinum-etoposide first line chemotherapy was administered in $113(68 \%)$ NEC and 12 (32\%) NET G3 patients. Disease control rate and progression free survival (PFS) were significantly higher in NEC compared to NET G3 $(P<0.05)$, whereas OS was significantly longer in NET G3 $(P=0.003)$. Second- and third-line therapies (mainly FOLFIRI and FOLFOX) were given in 79 and 39 of NEC patients; median PFS and OS were 3.0 and 7.6 months respectively after second-line and 2.5 and 6.2 months after third-line chemotherapy. In conclusion, NET G3 and NEC are characterized by significant differences in Ki-67 index and outcomes. While platinum-based chemotherapy is effective in NEC, it seems to have limited value in NET G3.
\end{abstract}

Endocrine-Related Cancer (2015) 22, 657-664
(C) 2015 Society for Endocrinology Printed in Great Britain

\section{Key Words}

- gastrointestinal cancer

- neuroendocrine carcinoma

- grade 3 NET

- Ki-67 index

- chemotherapy 


\section{Introduction}

Gastroenteropancreatic neuroendocrine neoplasms (GEPNEN) are rare tumors defined by the presence of specific biomarkers (Yao et al. 2008). The differentiation status is a major prognostic factor, regardless of primary site and stage (Lepage et al. 2004, Rindi et al. 2006, Yao et al. 2008). Moreover, the European Neuroendocrine Tumor Society (ENETS) developed a grading system (G1-G3) (Rindi et al. 2006), which has a strong prognostic value for survival (Ferrone et al. 2007, Pape et al. 2008, Jann et al. 2011, Panzuto et al. 2011, Khan et al. 2013). Grade 3 neoplasms (defined as having a high proliferative index with a Ki-67 $>20 \%$ ) are highly heterogeneous, containing tumors that are both well and poorly differentiated. The assumption that all NEN G3 should be considered as a single entity regarding diagnosis, prognosis and treatment has been challenged. Sorbye et al. (2013) proposed separating NEN G3 into two categories: those with a Ki-67 index ranging from 20 to $55 \%$ and those with a Ki- 67 index above $55 \%$. According to the current World Health Organization (WHO) 2010 Classification, neuroendocrine carcinoma (NEC) is defined by both a poorly differentiated morphology (large-cell or small-cell type) and a proliferative activity defined by mitotic count $>20 / 10 \mathrm{HPF}$ and/or Ki-67 index $>20 \%$ (Bosman et al. 2010). However, another subgroup of NEN that are not included in the recent WHO classification show a well-differentiated morphology, although associated with a G3 grade (neuroendocrine tumor (NET) G3) (Velayoudom-Cephise et al. 2013, Basturk et al. 2014). Based on their data, Velayoudom-Cephise et al. proposed a new classification for NEN G3 based on the combination of morphology and grade.

Data on NEN G3 are limited and retrospective:

i) GEP-NEC accounts for $\sim 10-20 \%$ of all GEP-NEN (Lepage et al. 2004, Yao et al. 2008); they have a poor prognosis with a median survival of only 4-6 months in stage IV disease without treatment and up to 6-19 months in patients receiving the standard first-line, platinum-etoposide chemotherapy. In the course of the disease, almost all NEC show resistance to first-line chemotherapy. However, second-line treatment is not codified (Moertel et al. 1991, Mitry et al. 1999, Fjallskog et al. 2001, Janson et al. 2010, Strosberg et al. 2010, Oberg et al. 2012). The types and benefits of second-line therapeutic regimens still have to be evaluated.

ii) Data on GEP-NET G3 are even more limited; they account for $\sim 10 \%$ of G3-GEP-NEN (Scoazec etal. 2012). NET G3 appear to have a significantly more protracted clinical course than NEC. First-line therapy is not codified. It might be expected that they benefit from less aggressive chemotherapeutic regimens routinely used in NET G2 (e.g., temozolomide-based therapy).

The aim of this study was to describe characteristics, prognosis and response to treatment of GEP-NEN G3, comparing NET G3 (defined, as above: well-differentiated NET with a G3 grading) and NEC (Table 1). For this purpose, we performed a retrospective analysis of a cohort of 204 patients with GEP-NEN G3, from eight European centers.

\section{Patients and methods}

Patients were identified from hospital chart codings and hospital databases. The inclusion criteria were: i) initial diagnosis of NEN G3 from January 2000 to December 2013, ii) histopathologically confirmed diagnosis by synaptophysin (Syn) and/or chromogranin A (CgA) positivity, iii) GEP primary or of unknown primary and iv) Ki-67 index $>20 \%$ or poorly differentiated morphology. Mixed tumors (MANEC) and NEN G3 without morphological differentiation available were excluded. Regarding quality of the pathology data, all the centers involved are tertiary hospitals that have expert pathologists in NET reviewing the samples before multidisciplinary meetings.

Data captured included demographics (name of NET center, age at diagnosis, gender, date of diagnosis); clinical

Table 1 Neuroendocrine neoplasm Grade 3 (NEN G3) represents two groups regarding the morphology and the grading: neuroendocrine carcinoma (NEC) and neuroendocrine tumor Grade 3 (NET G3)

\section{Neuroendocrine neoplasm}

Neuroendocrine tumor Grade 1

Neuroendocrine tumor Grade 2

Neuroendocrine tumor Grade 3

Neuroendocrine carcinoma

\section{Morphology (differentiation)}

Well-differentiated

Well-differentiated

Well-differentiated

Poorly-differentiated (large or small cell)

\begin{tabular}{c} 
Grading G1-G3 (Ki-67 index in \%) \\
\hline G1 $(\leq 2 \%)$ \\
G2 (3-20\%) \\
G3 (>20\%) \\
G3 (>20\%)
\end{tabular}

\begin{tabular}{c} 
Abbreviation \\
\hline NET G1 \\
NET G2 \\
NET G3 \\
NEC
\end{tabular}

http://erc.endocrinology-journals.org DOI: 10.1530/ERC-15-0119
(C) 2015 Society for Endocrinology Printed in Great Britain
Published by Bioscientifica Ltd 
presentation (primary tumor site, presence of metastases, site of metastases, functionality); imaging modalities (conventional imaging, fludeoxyglucose (18F), positron emission tomography (FDG-PET), somatostatin receptor imaging); pathology (origin and type of tissue specimen, TNM stage (ENETS), Ki-67 index/mitotic count, differentiation, cell size, immunohistochemistry (CgA, Syn)); treatment (surgical intervention, first-, second- and third-line chemotherapy) and follow-up. Response to chemotherapy was analyzed according to the following criteria: type of regimen, start and end date of chemotherapy, best response (local radiological review), progression free survival (PFS) and overall survival (OS).

\section{Statistical analysis}

Categorical variables were expressed as percentages and compared by the $\chi^{2}$-test or with Fisher's exact test, as appropriate. Continuous variables were expressed as medians with the range. PFS was calculated from the initiation of chemotherapy to the date of disease progression, according to local radiologic assessment or death from any cause, whichever occurred first. OS was calculated from the initiation of each chemotherapy line to the date of death or last follow-up. PFS and OS were assessed using Kaplan-Meier analysis and comparisons were performed using the log-rank test. A $P$ value of $<0.05$ was considered statistically significant. Cox proportional

Table 2 Patient and tumor characteristics

Characteristics
Number, $n$ (\%)
Age, median (range), years
Male, $n$ (\%)
Functional tumours, $n$ (\%)
Primary tumour location, $n$ (\%)
Pancreas
Colon
CUP
Rectum
Stomach
Other
Small bowel
Esophagus
Duodenum
Stage, $n$ (\%)
I-II
III
IV
Number of metastatic sites, $n(\%)$
0
1
M 1
Metastatic sites, $n(\%)$
Liver
Peritoneal
Lung
Brain
Bone
Lymphatic
Other
Positive FDG-PET, $n(\%)$
Positive SRS, $n(\%)$
Synaptophysin,$+ n(\%)$
Chromogranin A,$+ n(\%)$
Cell size for NEC, $n(\%)$
Small cell
Large cell
Ki-67 index, median (range)
Surgery of primary tumour, $n(\%)$

\begin{tabular}{|c|c|}
\hline All cases & NET G3 \\
\hline $204(100)$ & $37(18)$ \\
\hline $63(21-89)$ & $52(22-78)$ \\
\hline $122(60)$ & $20(54)$ \\
\hline $9(4)$ & $5(14)$ \\
\hline $65(32)$ & $24(65)$ \\
\hline $31(15)$ & $0(0)$ \\
\hline $28(14)$ & $3(8)$ \\
\hline $24(12)$ & $3(8)$ \\
\hline $17(8)$ & $3(8)$ \\
\hline $13(6)$ & $1(3)$ \\
\hline $11(5)$ & $2(5)$ \\
\hline $8(4)$ & $0(0)$ \\
\hline $7(3)$ & $1(3)$ \\
\hline $15(7)$ & $4(11)$ \\
\hline $44(22)$ & $10(27)$ \\
\hline $145(71)$ & $23(62)$ \\
\hline $25(12)$ & $5(14)$ \\
\hline $79(41)$ & $18(49)$ \\
\hline $91(44)$ & $14(38)$ \\
\hline 137 (67) & $29(78)$ \\
\hline $33(16)$ & 5 (14) \\
\hline $19(9)$ & $2(5)$ \\
\hline $5(3)$ & $0(0)$ \\
\hline 25 (12) & 7 (19) \\
\hline $81(40)$ & $14(38)$ \\
\hline $22(10)$ & $4(11)$ \\
\hline 65/76 (86) & 9/12 (75) \\
\hline $44 / 82(54)$ & 21/24 (92) \\
\hline $184 / 192$ (96) & $33 / 34$ (97) \\
\hline \multirow[t]{3}{*}{$147 / 189$ (78) } & $32 / 35(91)$ \\
\hline & - \\
\hline & - \\
\hline $70(21-100)$ & $30(21-70)$ \\
\hline $82(40)$ & $22(60)$ \\
\hline
\end{tabular}

\begin{tabular}{|c|c|}
\hline NEC & $\boldsymbol{P}$ \\
\hline \multicolumn{2}{|l|}{167 (79) } \\
\hline $64(21-89)$ & 0.001 \\
\hline $102(61)$ & 0.46 \\
\hline \multirow[t]{2}{*}{$4(2)$} & 0.003 \\
\hline & 0.001 \\
\hline \multicolumn{2}{|l|}{$41(25)$} \\
\hline \multicolumn{2}{|l|}{31 (19) } \\
\hline \multicolumn{2}{|l|}{25 (15) } \\
\hline \multicolumn{2}{|l|}{$21(13)$} \\
\hline \multicolumn{2}{|l|}{$14(8)$} \\
\hline \multicolumn{2}{|l|}{$12(7)$} \\
\hline \multicolumn{2}{|l|}{$9(5)$} \\
\hline \multicolumn{2}{|l|}{$8(5)$} \\
\hline \multicolumn{2}{|l|}{$6(4)$} \\
\hline & 0.41 \\
\hline \multicolumn{2}{|l|}{$11(7)$} \\
\hline \multicolumn{2}{|l|}{$34(20)$} \\
\hline \multicolumn{2}{|l|}{$122(73)$} \\
\hline & 0.46 \\
\hline
\end{tabular}

NET, neuroendocrine tumour; NEC, neuroendocrine carcinoma; SRS, somatostatin receptor imaging; CUP, carcinoma of unknown primary.

http://erc.endocrinology-journals.org DOI: 10.1530/ERC-15-0119
(C) 2015 Society for Endocrinology Printed in Great Britain 
hazard models were developed using relevant clinicopathologic variables to determine the association of each parameter with OS. For continuous variables, the cut-off level chosen was their median value; furthermore, only variables with a $P$ value of $<0.10$ at univariate analysis were introduced in the Cox model. Relative risks were expressed as hazard ratios (HRs) with 95\% CIs. The cut-off date for follow-up was July 1, 2014. All statistical analyses were performed using the Statistical Package for Social Sciences, version 20.0 (Chicago, IL, USA).

\section{Results}

\section{Patient characteristics}

Overall, 233 patients were included from eight tertiary centers. Twenty-nine (12\%) patients were excluded due to violation of inclusion/exclusion criteria. Characteristics of the remaining 204 patients included in this multi-centric retrospective study are summarized in Table 2 . The majority of the patients $(n=136,67 \%)$ were initially diagnosed from the beginning of 2010 onwards. The median time of follow-up of those patients alive was 14.5 (range 1.1-124.7) months. Patients were significantly younger in the NET G3 cohort $(P=0.001)$ and were significantly more likely to have a functional tumor compared to NEC $(P=0.003)$ (Table 2$)$. Primary localization was more often in the pancreas (65\%) for NET G3, while colorectal NEC was more common than colorectal NET G3 (Table 2). Nuclear medicine imaging did not identify a significant difference in FDG-PET uptake between both cohorts, but SRS uptake was more frequent and higher in NET G3 tumors.

\section{Histopathology}

Thirty-seven (18\%) and 167 (79\%) cases showed well differentiated or poorly differentiated morphological features respectively, defining them as NET G3 and NEC. The median Ki-67 value across all tumors was 70\% (range 21-100), with the distribution of Ki-67 values in relation to differentiation displayed in Fig. 1. Median Ki-67 in the NEC group (80\%, range: $25-100)$ was significantly higher than in NET G3 (30\%, range: $21-70 ; P<0.001)$. In those cases with Ki-67 $>55 \%$, almost all tumors were poorly differentiated, whereas the subgroup with a Ki-67 index of between 21 and 55\% were very heterogeneous in terms of differentiation (Fig. 1). A subgroup of NEC patients had the morphological description assessed according to the WHO 2010 definition; 55 (43\%) had small-cell and 73 (57\%) had

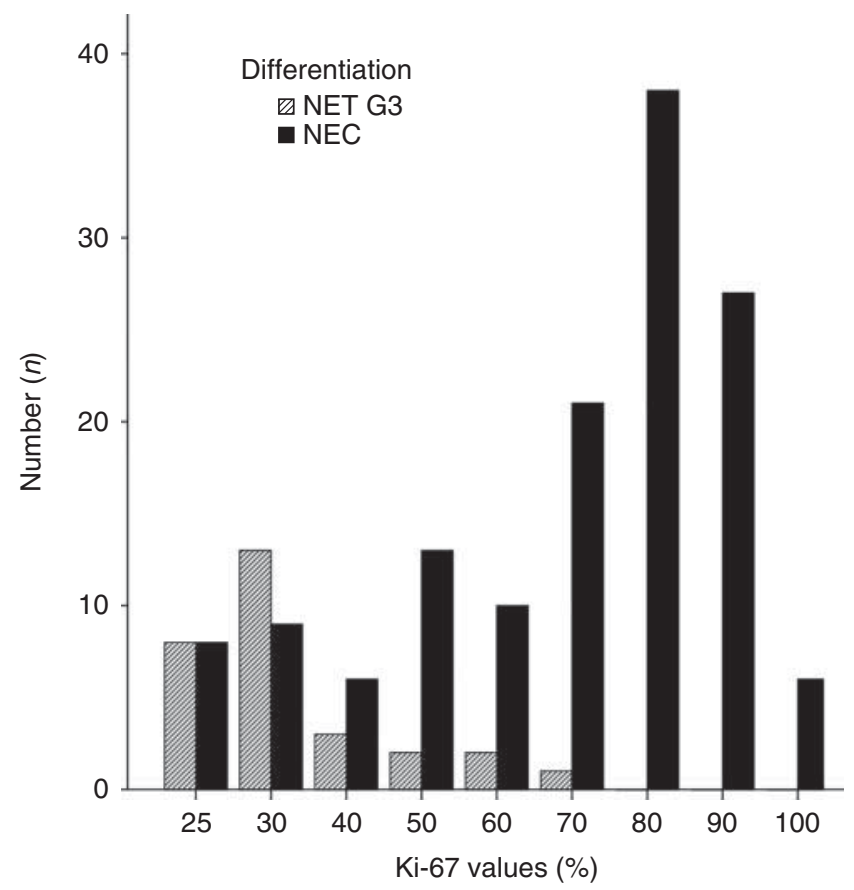

Figure 1

Ki-67 distribution according to differentiation in Grade 3 neuroendocrine neoplasms.

large-cell carcinoma. The Ki-67 index was significantly higher in small-cell NEC vs large-cell NEC (80\% vs 70\%; $P=0.025$ ). CgA and Syn staining were not significantly different between NET G3 and NEC, although NEC seemed to show less CgA staining ( $75 \%$ vs $91 \%, P=0.08$ ).

\section{Survival}

Over the study period, death was recorded in 110 of the patients (54\%). Median OS across all of the patients was 22.8 (95\% CI: 17.8-27.9) months (Fig. 2a) and was significantly higher (HR=8.3 (95\% CI: 2.9-23.81); $P<0.001)$ in NET G3 (median 98.7 months, 95\% CI: 53.9-143.5) than in NEC (median 17 months, 95\% CI 13.5-20.5) (Fig. 2b) after multivariate analysis. Results of univariate analysis and cox regression on other prognostic factors for survival are summarized in Table 3. TNM staging proved to be of prognostic relevance (Fig. 2c), with statistical significance according to both univariate and multivariate analysis. Ki-67 $>55 \%$ was associated with worse survival at univariate analysis, but not at multivariate analysis.

\section{Treatment}

Twelve (32\%) patients with NET G3 and 113 (68\%) patients with NEC were treated by a platinum-etoposide

Published by Bioscientifica Ltd. 

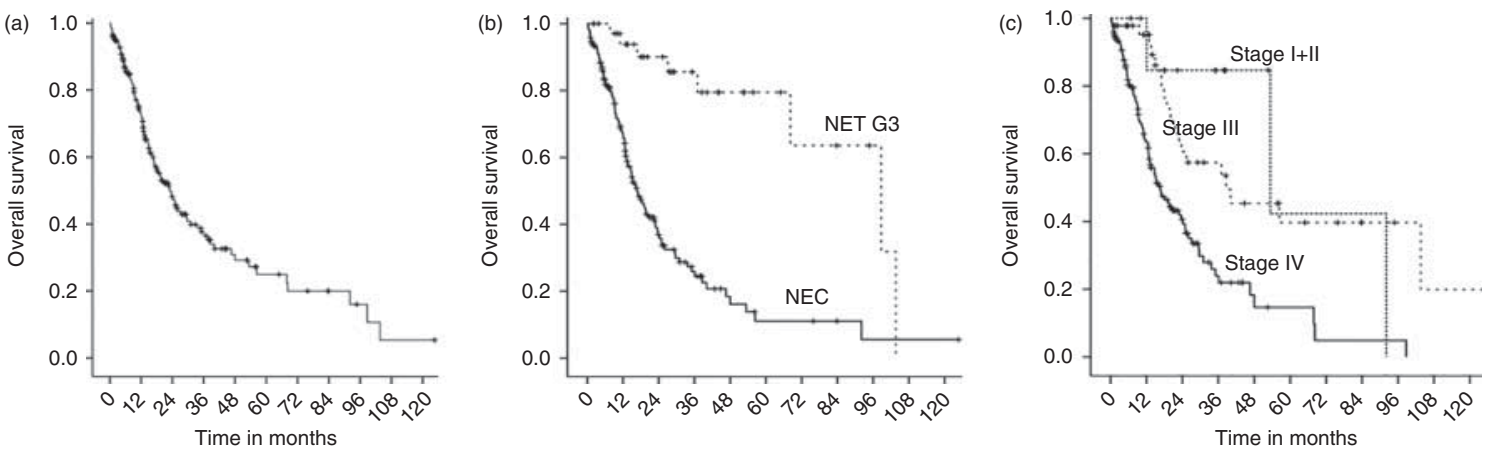

Figure 2

Survival in patients with Grade 3 neuroendocrine neoplasm, in the whole population (a) and according to differentiation (b), and TNM stage (c) after multivariate analysis.

first-line chemotherapy, $1.0(0-71.5)$ months after the diagnosis. In this platinum-treated population, disease control rate (DCR) $(33 \%$ vs $68 \% ; P=0.03)$ and median PFS (2.4 vs 5.0 months; $P=0.049$ ) were significantly lower in NET G3 compared to NEC respectively, while median OS remained significantly longer in NET G3 than in NEC patients $(P=0.003)$ (Table 4$)$. Among NEC patients, DCR was $31 / 40(77 \%)$ in small-cell vs $32 / 53(60 \%)$ in large-cell NEC $(P=0.08)$; DCR was $33 / 52(63 \%)$ in pancreatic and $21 / 33(64 \%)$ in colorectal primaries $(P=0.82)$. The other

Table 3 Univariate analysis and Cox regression on prognostic baseline factors for survival in patients with G3 neuroendocrine neoplasms

\begin{tabular}{|c|c|c|c|}
\hline \multirow[b]{2}{*}{ Characteristics } & \multirow{2}{*}{$\begin{array}{c}\text { Univariate analysis } \\
P \text { value }\end{array}$} & \multicolumn{2}{|c|}{ Multivariate analysis Cox regression } \\
\hline & & $\mathrm{HR}(95 \% \mathrm{Cl})$ & $P$ value \\
\hline Age, $\leq$ vs $>$ median of 63 years & 0.57 & & \\
\hline Gender, male vs female & 0.65 & & \\
\hline \multicolumn{4}{|l|}{ Primary location } \\
\hline CUP vs other & 0.04 & $0.46(0.21-1)$ & 0.052 \\
\hline Duodeno-pancreatic vs other & 0.06 & $0.61(0.32-1.16)$ & 0.13 \\
\hline Colorectal vs other & 0.07 & $0.52(0.27-1)$ & 0.051 \\
\hline Esophagus-stomach vs other & 0.36 & & \\
\hline Functionality, yes vs no & 0.057 & $1.42(0.38-5.36)$ & 0.6 \\
\hline TNM-staging & $<0.001$ & & \\
\hline Stage IV vs I+II & & $0.16(0.04-0.61)$ & 0.007 \\
\hline Stage IV vs III & & $0.48(0.21-0.98)$ & 0.045 \\
\hline Number of metastatic sites & $<0.001$ & & \\
\hline 0 vs 1 & & $1.5(0.37-6.13)$ & 0.58 \\
\hline 0 vs $>1$ & & $2.18(0.45-10.54)$ & 0.33 \\
\hline \multicolumn{4}{|l|}{ Type of metastatic sites } \\
\hline Liver metastases, yes vs no & 0.02 & $0.7(0.35-1.41)$ & 0.32 \\
\hline Peritoneal metastases, yes vs no & 0.009 & $0.79(0.43-1.45)$ & 0.45 \\
\hline Lung metastases, yes vs no & 0.02 & $0.58(0.27-1.25)$ & 0.16 \\
\hline Bone metastases, yes vs no & 0.5 & & \\
\hline Lymphatic metastases, yes vs no & 0.045 & $1.2(0.69-2.1)$ & 0.51 \\
\hline Brain metastases, yes vs no & 0.7 & & \\
\hline Other metastases, yes vs no & 0.18 & & \\
\hline FDG-PEG positivity, yes vs no & 0.15 & & \\
\hline SRS positivity, yes vs no & 0.23 & & \\
\hline NET G3 vs NEC & $<0.001$ & $8.3(2.9-23.81)$ & $<0.001$ \\
\hline Large vs small cell NEC & 0.87 & & \\
\hline Synaptophysin positivity, yes vs no & 0.39 & & \\
\hline Chromogranin A positivity, yes vs no & 0.51 & & \\
\hline $\mathrm{Ki}-67, \leq 50 \%$ vs $>50 \%$ & $<0.001$ & $1.26(0.73-2.17)$ & 0.41 \\
\hline
\end{tabular}

HR, hazard ratio; NET, neuroendocrine tumor; NEC, neuroendocrine carcinoma; SRS, somatostatin receptor imaging; CUP, carcinoma of unknown primary. 
Table 4 Efficacy of platinum-etoposide first-line chemotherapy according to differentiation of Grade 3 neuroendocrine neoplasms

\begin{tabular}{|c|c|c|c|}
\hline & NET G3 & NEC & $\boldsymbol{P}$ \\
\hline Number of patients & 12 & 113 & \\
\hline OR, $n(\%)$ & $2(17)$ & $39(35)$ & 0.18 \\
\hline SD, $n(\%)$ & $1(8)$ & $25(22)$ & 0.24 \\
\hline PD, $n(\%)$ & $6(50)$ & $30(27)$ & 0.09 \\
\hline NA, $n(\%)$ & $3(25)$ & $19(17)$ & 0.36 \\
\hline DCR $(\%)$ & $3(33 \%)$ & $64(68 \%)$ & 0.036 \\
\hline $\begin{array}{l}\text { Median PFS }(95 \% \mathrm{Cl}) \text {, } \\
\text { months }\end{array}$ & $2.4(1.1-3.8)$ & $5.0(4.0-6.1)$ & 0.049 \\
\hline $\begin{array}{l}\text { Median OS }(95 \% \mathrm{Cl}) \text {, } \\
\text { months }\end{array}$ & NR & $16.4(13.4-19.5)$ & 0.003 \\
\hline
\end{tabular}

$\mathrm{OR}$, objective response; $\mathrm{SD}$, stable disease; $\mathrm{PD}$, progressive disease; $N A$, not available; $D C R$, disease control rate; PFS, progression free survival; OS, overall survival; NR, not reached.

treatments used in NET G3 were very heterogeneous and could not be compared with platinum-etoposide in this retrospective study. With regard to the subgroup of patients with NEC, 79 patients (48\%) and 39 patients (23\%) received second- and third-line chemotherapy, mainly irinotecan with fluorouracil and folinic acid (FOLFIRI), oxaliplatin with fluorouracil and folinic acid/ capecitabine (FOLFOX/Capox), or temozolomide-based chemotherapy. Efficacy of second- and third-line chemotherapy are displayed in Table 5; median PFS was $\sim 3$ months and 2.5 months respectively.

\section{Discussion}

With regard to the current WHO classification (2010), NEC is considered both, a tumor that is defined by its high proliferative activity and also by its poorly differentiated tumor morphology. Morphology has played an important role in defining tumors in the past, but now this parameter may be being neglected within routine care, as the definition of NEC is often given by just providing its grade. This is reflected by the most recent publications of NEN G3, where tumor morphology is not even mentioned (Welin et al. 2011, Sorbye et al. 2013). While most NEN G3 are of poorly differentiated morphology, there is a subgroup of well-differentiated NET with G3 grading that is not reflected by the latest WHO classification. Furthermore, although Ki-67 is key to the grading system adopted by WHO, we show that morphology was found to be more informative than the Ki-67 index to stratify NEN G3 patients outcomes. Usually, NET G3 have a consistently lower Ki-67 index compared to NEC, ranging between 20 and $50 \%$.
Several studies have challenged the assumption that NET G3 and NEC are overlapping entities. It has been suggested that these two cancers differ in terms of prognosis, SRS uptake and response to chemotherapy regimens (Vilar et al. 2007, Velayoudom-Cephise et al. 2013). The response to first-line platinum-etoposide represents one of the most relevant disparities. Velayoudom-Cephise et al. (2013) reported 0\% objective response in NET G3 patients vs 31\% in large-cell NEC patients. This was in agreement with the results of the NORDIC study, which compared subgroups with Ki- $67<55 \%$ vs $>55 \%$, recording objective response rates of $15 \%$ vs $42 \%$ respectively (Sorbye et al. 2013). In our study, the response rates to platinum-etoposide were similar to those reported in the above-mentioned studies (39\% vs $2 \%$ for NEC and NET G3 respectively), underlining the fact that differentiation is key when considering the sensitivity to the standard first-line chemotherapy. We hypothesize that NET G3 could have been enrolled in Sorbye's study, explaining the lower response rate to platinum-etoposide within the group of tumors with a Ki-67 $<55$, particularly from pancreas localization. Among our NEC patients, we reported similar responses between duodeno-pancreatic and colorectal primaries. A trend exists of better response to platinum-etoposide in smallcell vs large-cell NEC. Limited data and no guidelines are currently available for managing patients with NET G3. The observation that most experts feel these cases to be different from NEC is supported by their first choice to use

Table 5 Type and efficacy of second-line and third-line chemotherapies in poorly differentiated NEC

\begin{tabular}{|c|c|c|}
\hline & Second-line & Third-line \\
\hline Number of patients (\%) & $79(48 \%)$ & $39(23 \%)$ \\
\hline \multicolumn{3}{|l|}{ Type of regimen, $n$ (\%) } \\
\hline FOLFIRI & $30(38)$ & $11(28)$ \\
\hline FOLFOX/Capox & $14(18)$ & 7 (18) \\
\hline Platinum/etoposide & $12(15)$ & $3(8)$ \\
\hline Temozolomide-based & $7(9)$ & $4(10)$ \\
\hline $\begin{array}{l}\text { Clinical trials testing } \\
\text { sunitinib }\end{array}$ & $3(4)$ & $1(3)$ \\
\hline Other $^{\mathrm{a}}$ & $13(16)$ & $13(33)$ \\
\hline Objective response, $n(\%)$ & $12(16)$ & $4(10)$ \\
\hline Stable disease, $n(\%)$ & $15(20)$ & $3(8)$ \\
\hline Progressive disease, $n(\%)$ & $38(50)$ & $19(49)$ \\
\hline Not available, $n(\%)$ & $12(16)$ & $13(33)$ \\
\hline $\begin{array}{l}\text { Median progression free } \\
\text { survival }(95 \% \mathrm{Cl}) \text { in months }\end{array}$ & $2.98(2.56-3.41)$ & $2.53(1.38-3.67)$ \\
\hline $\begin{array}{l}\text { Median overall survival } \\
(95 \% \mathrm{Cl}) \text { in months }\end{array}$ & $7.64(6.42-8.86)$ & $6.2(3.78-8.62)$ \\
\hline
\end{tabular}

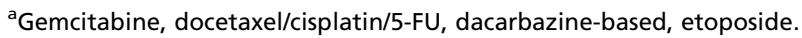

Published by Bioscientifica Ltd. 
alternative regimens than cisplatin/etoposide in the majority of NET G3 patients. In tertiary specialized NET centers, alternative treatment modalities, such as temozolomide/capecitabine and FOLFOX, routinely used in NET G2, are the preferred choice over platinum/etoposide chemotherapy for NET G3.

Another unanswered issue is the selection of therapy after the failure of a platinum-based regimen in NEC; second-line treatments are not yet established. Alternative regimens include temozolomide combinations, FOLFIRI, FOLFOX and topotecan (Welin et al. 2011, Hentic et al. 2012, Olsen et al. 2012, Olsen et al. 2014, Hadoux et al. 2015). Published trials have included very heterogeneous populations, which make direct comparisons impossible. In particular, a retrospective study of temozolomide \pm capecitabine \pm bevacizumab in 25 patients included mainly patients with a Ki-67 between 20 and $30 \%$; it reported an objective response rate of $32 \%$ (Welin et al. 2011). However, it is difficult to recommend temozolomide as an optional treatment for all NEN G3 based on this analysis, or for all NET G3 irrespective of their primary tumor site. Furthermore, the morphological feature was not a variable considered in this particular report. On the contrary, a study reported the efficacy of FOLFIRI as second-line therapy in a NEC population with a median Ki-67 of 50\%, excluding NET G3 (Hentic et al. 2012). Similar results were obtained by Hadoux et al. (2015) using FOLFOX in a similar population. A retrospective study, using topotecan in 22 patients with clearly poorly differentiated tumors with a median Ki-67 of 95\%, showed no convincing anti-tumor activity (Olsen et al. 2014).

Our study presents one of the largest well-characterized cohorts of NEN G3. We analyzed these data with the aim of generating hypotheses to drive further clinical trials. In this respect, retrospective series are key to generating new approaches in this rare disease in which it is difficult to conduct randomized trials. Retrospective collection of data has common well-known biases, such as the detection bias (the data collected are those from the longest survivors). Another potential weakness of this study was the lack of blinded centralized pathology review to ensure perfect accuracy regarding classification of morphology; however, all centers were expert NET groups with recognized and experienced pathologists in this field. In addition, all the centers recruiting patients were tertiary hospitals, which might have affected the patient survival and the chemotherapy schedules applied.

In conclusion, in our study, differentiation was the strongest independent factor for OS. Grade 3 NEN represent a heterogeneous disease that makes clinical decisions extremely difficult. Strikingly, platinum-based chemotherapy was not the first choice of treatment for NET G3 and seemed significantly less effective in NET G3 compared to NEC. This latter fact shows that within the NET expert community NET G3 and NEC are considered clearly a different entity. Finally, our study presents interesting data on the efficacy of second- and third-line treatment of NEC, which could be useful in designing new prospective studies.

\section{Previous presentation}

An abstract of this study was presented as an oral presentation at the 11th annual European Neuroendocrine Tumors Society (ENETS) meeting (Barcelona, March 2014), and was awarded first prize in the abstract category.

\section{Declaration of interest}

The authors declare that there is no conflict of interest that could be perceived as prejudicing the impartiality of the research reported.

\section{Funding}

This research did not receive any specific grant from any funding agency in the public, commercial or not-for-profit sector.

\section{Author contribution statement}

All authors: conception and design; collection and assembly of data; data analysis and interpretation; manuscript writing; and final approval for the manuscript.

\section{Acknowledgements}

The authors acknowledge the support of the Knowledge Network and the services of medical writer Josie Saulter of Echo Communications to review the article; both were funded by Ipsen. Knowledge Network: founded in 2010, the Knowledge Network is a continuous program of education, investigation and discussion focused on advancing the understanding and management of GEP-NET, supported by Ipsen.

\section{References}

Basturk O, Tang L, Hruban RH, Adsay V, Yang Z, Krasinskas AM, Vakiani E, La-Rosa S, Jang KT, Frankel WL et al. 2014 Poorly differentiated neuroendocrine carcinomas of the pancreas: a clinicopathologic analysis of 44 cases. American Journal of Surgical Pathology 38 437-447. (doi:10.1097/PAS.0000000000000169)

Bosman F, Carneiro F, Hruban R \& Theise N 2010 World Health Organization (WHO) Classification of Tumours of the Digestive System. Lyon, France: IARC Press.

Ferrone CR, Tang LH, Tomlinson J, Gonen M, Hochwald SN, Brennan MF, Klimstra DS \& Allen PJ 2007 Determining prognosis in patients with pancreatic endocrine neoplasms: can the WHO classification system be

Published by Bioscientifica Ltd. 
simplified? Journal of Clinical Oncology 25 5609-5615. (doi:10.1200/ JCO.2007.12.9809)

Fjallskog ML, Granberg DP, Welin SL, Eriksson C, Oberg KE, Janson ET \& Eriksson BK 2001 Treatment with cisplatin and etoposide in patients with neuroendocrine tumors. Cancer 92 1101-1107. (doi:10.1002/ 1097-0142(20010901)92:5<1101::AID-CNCR1426>3.0.CO;2-V)

Hadoux J, Malka D, Planchard D, Scoazec JY, Caramella C, Guigay J, Boige V, Leboulleux S, Burtin P, Berdelou A et al. 2015 Post-first-line FOLFOX chemotherapy for grade 3 neuroendocrine carcinoma. Endocrine-Related Cancer 22 289-298. (doi:10.1530/ERC-15-0075)

Hentic O, Hammel P, Couvelard A, Rebours V, Zappa M, Palazzo M, Maire F, Goujon G, Gillet A, Levy P et al. 2012 FOLFIRI regimen: an effective second-line chemotherapy after failure of etoposide-platinum combination in patients with neuroendocrine carcinomas grade 3 . Endocrine-Related Cancer 19 751-757. (doi:10.1530/ERC-12-0002)

Jann H, Roll S, Couvelard A, Hentic O, Pavel M, Muller-Nordhorn J, Koch M, Rocken C, Rindi G, Ruszniewski P et al. 2011 Neuroendocrine tumors of midgut and hindgut origin: tumor-node-metastasis classification determines clinical outcome. Cancer 1173332-3341. (doi:10.1002/cncr. 25855)

Janson ET, Sorbye H, Welin S, Federspiel B, Gronbaek H, Hellman P, Mathisen O, Mortensen J, Sundin A, Thiis-Evensen E et al. 2010 Nordic Guidelines 2010 for diagnosis and treatment of gastroenteropancreatic neuroendocrine tumours. Acta Oncológica 49 740-756. (doi:10.3109/ 0284186X.2014.941999)

Khan MS, Kirkwood A, Tsigani T, Garcia-Hernandez J, Hartley JA, Caplin ME \& Meyer T 2013 Circulating tumor cells as prognostic markers in neuroendocrine tumors. Journal of Clinical Oncology 31 365-372. (doi:10.1200/JCO.2012.44.2905)

Lepage C, Bouvier AM, Phelip JM, Hatem C, Vernet C \& Faivre J 2004 Incidence and management of malignant digestive endocrine tumours in a well defined French population. Gut 53 549-553. (doi:10.1136/gut. 2003.026401)

Mitry E, Baudin E, Ducreux M, Sabourin JC, Rufie P, Aparicio T, Aparicio T, Lasser P, Elias D, Duvillard P et al. 1999 Treatment of poorly differentiated neuroendocrine tumours with etoposide and cisplatin. British Journal of Cancer 81 1351-1355. (doi:10.1038/sj.bjc.6690325)

Moertel CG, Kvols LK, O'Connell MJ \& Rubin J 1991 Treatment of neuroendocrine carcinomas with combined etoposide and cisplatin. Evidence of major therapeutic activity in the anaplastic variants of these neoplasms. Cancer 68 227-232. (doi:10.1002/10970142(19910715)68:2<227::AID-CNCR2820680202>3.0.CO;2-I)

Oberg K, Knigge U, Kwekkeboom D \& Perren A 2012 Neuroendocrine gastro-entero-pancreatic tumors: ESMO Clinical Practice Guidelines for diagnosis, treatment and follow-up. Annals of Oncology 23 (Suppl 7) vii124-vii130.

Olsen IH, Sorensen JB, Federspiel B, Kjaer A, Hansen CP, Knigge U \& Langer SW 2012 Temozolomide as second or third line treatment of patients with neuroendocrine carcinomas. ScientificWorldJournal 2012170496. (doi:10.1100/2012/170496)

Olsen IH, Knigge U, Federspiel B, Hansen CP, Skov A, Kjaer A \& Langer SW 2014 Topotecan monotherapy in heavily pretreated patients with progressive advanced stage neuroendocrine carcinomas. Journal of Cancer 5 628-632. (doi:10.7150/jca.9409)

Panzuto F, Boninsegna L, Fazio N, Campana D, Pia Brizzi M, Capurso G, Scarpa A, De Braud F, Dogliotti L, Tomassetti P et al. 2011 Metastatic and locally advanced pancreatic endocrine carcinomas: analysis of factors associated with disease progression. Journal of Clinical Oncology 29 2372-2377. (doi:10.1200/JCO.2010.33.0688)

Pape UF, Jann H, Muller-Nordhorn J, Bockelbrink A, Berndt U, Willich SN, Koch M, Rocken C, Rindi G \& Wiedenmann B 2008 Prognostic relevance of a novel TNM classification system for upper gastroenteropancreatic neuroendocrine tumors. Cancer 113 256-265. (doi:10.1002/cncr.23549)

Rindi G, Kloppel G, Alhman H, Caplin M, Couvelard A, de Herder WW, Erikssson B, Falchetti A, Falconi M, Komminoth P et al. 2006 TNM staging of foregut (neuro)endocrine tumors: a consensus proposal including a grading system. Virchows Archiv 449 395-401. (doi:10.1007/s00428-006-0250-1)

Scoazec JY, Couverlard A, Monges G, Leteurtre E, Belleannée G, Guyetant S, Duvillard P, Danjoux M, Parot X \& Lepage C 2012 Well-differentiated grade 3 digestive neuroendocrine tumors: myth or reality? The PRONET Study Group. Journal of Clinical Oncology 30 (Supplement) abstract 4129. (available at: http://meetinglibrary.asco.org/content/ 100442-114)

Sorbye H, Welin S, Langer SW, Vestermark LW, Holt N, Osterlund P, Dueland S, Hofsli E, Guren MG, Ohrling K et al. 2013 Predictive and prognostic factors for treatment and survival in 305 patients with advanced gastrointestinal neuroendocrine carcinoma (WHO G3): the NORDIC NEC study. Annals of Oncology 24 152-160. (doi:10.1093/ annonc/mds276)

Strosberg JR, Coppola D, Klimstra DS, Phan AT, Kulke MH, Wiseman GA \& Kvols LK 2010 The NANETS, consensus guidelines for the diagnosis and management of poorly differentiated (high-grade) extrapulmonary neuroendocrine carcinomas. Pancreas 39 799-800. (doi:10.1097/ MPA.0b013e3181ebb56f)

Velayoudom-Cephise FL, Duvillard P, Foucan L, Hadoux J, Chougnet CN, Leboulleux S, Malka D, Guigay J, Goere D, Debaere T et al. 2013 Are G3 ENETS neuroendocrine neoplasms heterogeneous? Endocrine-Related Cancer 20 649-657. (doi:10.1530/ERC-13-0027)

Vilar E, Salazar R, Perez-Garcia J, Cortes J, Oberg K \& Tabernero J 2007 Chemotherapy and role of the proliferation marker Ki-67 in digestive neuroendocrine tumors. Endocrine-Related Cancer 14 221-232. (doi:10.1677/ERC-06-0074)

Welin S, Sorbye H, Sebjornsen S, Knappskog S, Busch C \& Oberg K 2011 Clinical effect of temozolomide-based chemotherapy in poorly differentiated endocrine carcinoma after progression on first-line chemotherapy. Cancer 117 4617-4622. (doi:10.1002/ cncr.26124)

Yao JC, Hassan M, Phan A, Dagohoy C, Leary C, Mares JE, Abdalla EK, Fleming JB, Vauthey JN, Rashid A et al. 2008 One hundred years after "carcinoid": epidemiology of and prognostic factors for neuroendocrine tumors in 35,825 cases in the United States. Journal of Clinical Oncology 26 3063-3072. (doi:10.1200/JCO.2007.15.4377)

Received in final form 22 June 2015

Accepted 23 June 2015

Made available online as an Accepted Preprint

25 June 2015 http://erc.endocrinology-journals.org

DOI: 10.1530/ERC-15-0119
(C) 2015 Society for Endocrinology Printed in Great Britain
Published by Bioscientifica Ltd. 